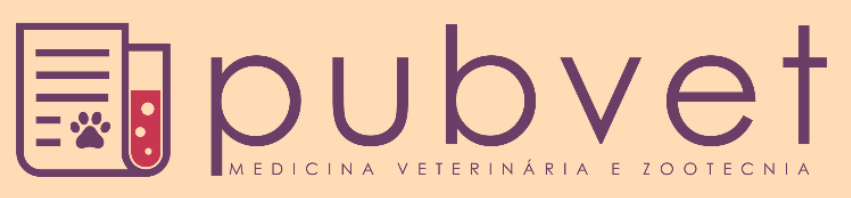

https://doi.org/10.31533/pubvet.v15n07a855.1-5

\title{
Mixossarcoma cutâneo em cão: Relato de caso
}

\author{
Charles Savi Mundo Dal Zotto ${ }^{1 *} \bullet$, Suélen Dalegrave ${ }^{2} \bullet$, Laís Rezzadori Flecke ${ }^{3} \bullet$, Denise \\ Masteguin $^{1 \bullet}$, Renata Lima da Roza ${ }^{\ominus}{ }^{4}$, Kleber Tochetto Gomes ${ }^{1}{ }^{\bullet}$, Eduardo Conceição de \\ Oliveira $^{50}(\mathbb{D}$
}

${ }^{1}$ Médico(a) veterinário(a) de Caxias do Sul-RS Brasil.

${ }^{2}$ Aprimoranda do Programa de Aprimoramento de Clínica Médica e Cirúrgica de Pequenos Animais, Pontifícia Universidade Católica do Paraná, Toledo - PR Brasil. ${ }^{3}$ Aprimoranda do Programa de Aprimoramento de Clínica Médica e Cirúrgica de Pequenos Animais, Universidade de Caxias do Sul, Caxias do Sul - RS Brasil. ${ }^{4}$ Discente do Curso de Medicina Veterinária da Universidade de Caxias do Sul, Caxias do Sul - RS Brasil.

${ }^{5}$ Docente da Universidade de Caxias do Sul, Patologia Veterinária, Caxias do Sul-RS Brasil.

*Autor para correspondência, E-mail: suhdalegrave@hotmail.com

Resumo. O mixossarcoma (MXS) é classificado como uma neoplasia rara, como grande parte dos Sarcomas de Tecidos Moles (STM), se manifesta como um tumor de caráter invasivo, com margem mal definida, baixo potencial metastático e crescimento lento. Acomete animais de meia idade a idosos, sem predileção sexual, e devido à pouca resposta aos protocolos quimioterápicos, o tratamento de eleição é a remoção cirúrgica. O objetivo foi relatar o atendimento de uma cadela idosa com diagnóstico de mixossarcoma de pele. $\mathrm{O}$ animal foi encaminhado para consulta apresentando aumento de volume na região cervical cranial. No exame físico apresentou massa com consistência mole, aderida em região tóraco-esternal. A paciente foi submetida a citologia e procedimento de exérese de neoplasia cutânea. Como protocolo terapêutico, foi prescrito anti-inflamatório, antibiótico e medicação para controle de dor. O caso apresentou duas recidivas em um período de 61 dias após a primeira cirurgia, com a realização da retirada cirúrgica em três momentos. No segundo procedimento, o tutor aceitou encaminhar material para histopatologia, confirmando diagnóstico de mixossarcoma. No terceiro procedimento cirúrgico para exérese de material neoplásico cutâneo recidivante, animal veio a óbito. Este trabalho demonstra a importância do diagnóstico precoce, por meio de exame histopatológico e assim uma conduta terapêutica precoce com uma ampla margem cirúrgica.

Palavras-chave: Histopatologia, mixossarcoma, recidivas, sarcoma de tecidos moles

\section{Cutaneous Myxosarcoma in a dog: Case report}

\begin{abstract}
Myxosarcoma (MXS) is classified as a rare neoplasm, as a large part of Soft Tissue Sarcomas (STM), and most often affects the skin, with an invasive character, with an ill-defined margin, low metastatic potential and slow growth. It affects middle-aged animals to the elderly, without sexual predilection, and due to the low response to chemotherapy protocols, the treatment of choice is surgical removal. The objective was to report the care of an elderly dog with a diagnosis of skin myxosarcoma. The animal was referred for consultation with an increase in volume in the cranial cervical region. On physical examination, the mass presented a soft consistency, adhered to the thoraco-sternal region. The patient underwent cytology and cutaneous neoplasia excision procedure. As a therapeutic protocol, meloxicam $0.1 \mathrm{mg} / \mathrm{kg}$ was prescribed every 25 hours for 3 days, metronidazole, $25 \mathrm{mg} / \mathrm{kg}$, every 12 hours for 7 days, dipyrone, $25 \mathrm{mg} / \mathrm{kg}$, every 12 hours and tramadol hydrochloride, $3 \mathrm{mg} / \mathrm{kg}$, every 12 hours for 5 days. The case presented two recurrences in a period of 61 days after the first surgery, with the surgical procedure performed three times. In the second procedure, the tutor agreed to send material for
\end{abstract}


histopathology, confirming myxosarcoma diagnosis. In the third surgical procedure for excision of recurrent cutaneous neoplastic material, the animal died. This work demonstrates the importance of early diagnosis, by means of histopathological examination and thus an early therapeutic approach and also the low incidence of cases of this neoplasm.

Keywords: Histopathology, myxosarcoma, recurrences, soft tissue sarcoma

\section{Mixosarcoma cutáneo en un perro: Reporte de un caso}

Resumen. El mixosarcoma (MXS) se clasifica como una neoplasia rara, en gran parte de los sarcomas de tejidos blandos (STM), y afecta con mayor frecuencia el tejido cutáneo, de carácter invasivo, con margen mal definido, bajo potencial metastásico y crecimiento lento. Afecta animales de mediana edad a ancianos, sin predilección sexual, y debido a baja respuesta a los protocolos de quimioterapia, el tratamiento de elección es la extirpación quirúrgica. El objetivo fue reportar el cuidado de un perro anciano con diagnóstico de mixosarcoma cutáneo. El animal fue remitido para consulta por aumento de volumen en la región cervical craneal. Al examen físico la masa presentaba una consistencia blanda, adherida a la región toracoesternal. La paciente fue sometida a citología y escisión de neoplasia cutánea. Como protocolo terapéutico se prescribió antinflamatorio, antibiótico y medicación para control del dolor. El caso presentó dos recurrencias en un período de 61 días después de la primera cirugía, realizándose el procedimiento quirúrgico en tres ocasiones. Durante el segundo procedimiento, el tutor accedió a enviar material para histopatología, confirmando el diagnóstico de mixosarcoma. En el tercer procedimiento quirúrgico para la escisión de material neoplásico cutáneo recurrente, el animal murió. Este trabajo demuestra la importancia del diagnóstico precoz, mediante el examen histopatológico y por tanto un abordaje terapéutico precoz y también la baja incidencia de casos de esta neoplasia.

Palabras clave: Histopatología, mixosarcoma, recidivas, sarcoma de tejidos blandos

\section{Introdução}

O mixossarcoma (MXS) é classificado como um Sarcoma de Tecidos Moles (STM), considerado uma neoplasia rara e maligna, de crescimento lento e com baixo índice de metástases. Acomete animais de meia idade a idosos e não tem predileção sexual (Ettinger et al., 2002; Gross et al., 2009; Liptak \& Withrow, 2007). Origina-se de fibroblastos ou células mesenquimais primitivas, que passam a produzir grande quantidade de mucina além do colágeno (Goldschmidt \& Hendrick, 2008).

Os tumores apresentam crescimentos infiltrativos de consistência mole, sem delimitação ou forma definida. Os locais mais atingidos pelo mixossarcoma são o tecido subcutâneo na região do tronco e membros, mas existem casos relatados em outras estruturas anatômicas (Hendrick, 2017; Liptak \& Withrow, 2007; Meuten, 2016).

O presente relato tem por objetivo descrever aspectos clínicos e patológicos de um mixossarcoma cutâneo recidivante em um cão.

\section{Relato de caso}

Foi atendido uma cadela, sem raça definida, castrada, 15 anos, pesando $10,5 \mathrm{~kg}$. A tutora relatou que nos últimos meses notou um progressivo aumento de volume na região do esterno se estendendo até a região axilar, e a pouco tempo, ocorreu um provável trauma devido a brigas com outros animais.

Ao exame físico observou-se nível de consciência alerta, bom estado corporal, mucosas normocoradas, temperatura retal de $38^{\circ} \mathrm{C}$, tempo de preenchimento capilar (TPC) de um segundo e pulso forte. A frequência cardíaca e respiratória dentro dos padrões, sem alterações em linfonodos superficiais, com exceção dos linfonodos axilares que não puderam ser palpáveis devido ao aumento de volume na região. A massa localizada na região tóraco-esternal tinha consistência macia, não ulcerada, sem delimitações de bordas e estendia-se por aproximadamente toda a região peitoral e de axilas. 
Foi coletada amostra sanguínea para análise de hemograma e bioquímica sérica, os quais não apresentaram alterações significativas. A citologia aspirativa por agulha fina (CAAF) do aumento de volume esternal, sugeriu neoplasia mesenquimal. Foi indicado fazer exame radiológico torácico, afins de estadiamento neoplásico, porém a tutora não aceitou.

A canina foi encaminhada para exérese de massa, e durante o procedimento constatou-se que a estrutura se encontrava profundamente infiltrada na musculatura, apresentando aspecto extremamente friável, não sendo possível sua remoção total. Após síntese habitual, foi fixado dreno subcutâneo. Aconselhou-se a realização de histopatologia do fragmento removido, contudo os tutores não autorizaram. O animal obteve alta hospitalar no mesmo dia, prescrito meloxicam $0,1 \mathrm{mg} / \mathrm{kg}$, a cada 25 horas por três dias, metronidazol $25 \mathrm{mg} / \mathrm{kg}$ a cada 12 horas por sete dias, dipirona $25 \mathrm{mg} / \mathrm{kg}$ a cada 12 horas por cinco dias e cloridrato de tramadol $3 \mathrm{mg} / \mathrm{kg}$ a cada 12 horas por cinco dias, uso de roupa cirúrgica até retirada dos pontos e dreno e retorno em três dias para reavaliação e troca de curativo. Os pontos foram retirados 10 dias após a realização do procedimento, com bom padrão cicatricial.

No quadragésimo primeiro dia após o procedimento cirúrgico, o caso apresentou recidiva local, a massa tumoral apresentava-se ulcerada e hiperêmica e se estendia por toda região peitoral (Figura 1) realizou-se uma segunda cirurgia, nos mesmos padrões operatórios e terapêutica pós-operatória utilizados no procedimento anterior. As amostras recolhidas foram encaminhadas ao Setor de Patologia Veterinária da Universidade Federal do Rio Grande do Sul (SPV-UFRGS), para realização de exame histopatológico. A análise da massa indicou mixossarcoma de pele, em derme profunda e estendendose ao tecido subcutâneo onde foi caracterizada por uma neoplasia não delimitada, de células fusiformes em disposição de feixes, por vezes ninhos, células alongadas, com núcleos ovalados, citoplasma disperso e levemente granular, nucléolos conspícuos e cromatina pontilhada; apresentando anisocariose moderada, e com tecido mixoide entremeando a celularidade neoplásica com índice mitótico médio (Figura 2).

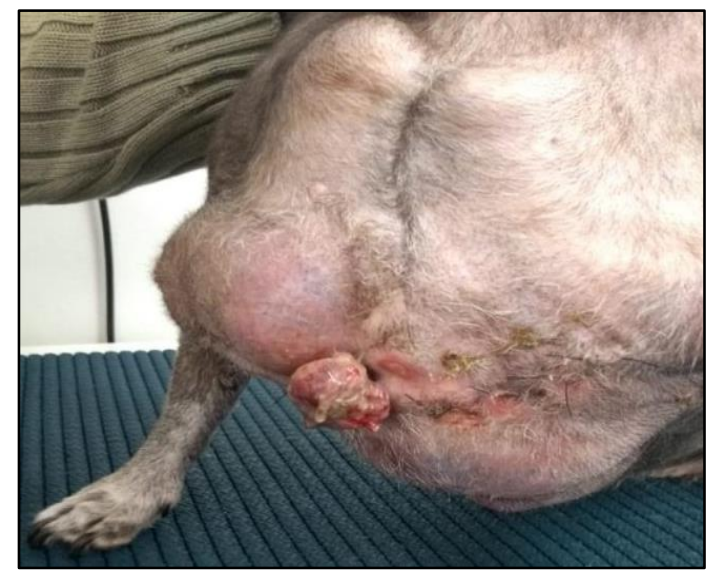

Figura 1. Cadela, SRD apresentando massa neoplásica em região toracoesternal antecedendo segunda cirurgia.

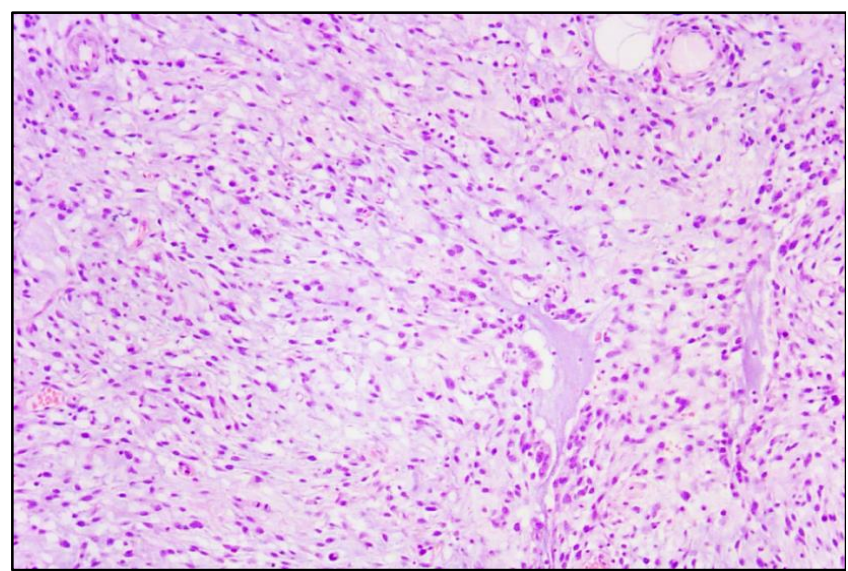

Figura 2. Canino com mixosarcoma cutâneo: proliferação de células mesenquimais entremeadas por material mixoide. HE, obj. 20

No mixossarcoma foi observado uma proliferação neoplásica de células mesenquimais arranjadas em feixes frouxos e entremeadas por abundante matriz mixoide, moderada anisocitose e anisocariose, células binucleadas. Adjacente ao tumor observou-se área focalmente extensa de necrose associada à deposição de fibrina, infiltrado inflamatório de linfócitos e trombose. Demais órgãos não apresentaram alterações histológicas.

No retorno, no sexagésimo primeiro dia da primeira cirurgia, observou-se um novo aumento de volume com áreas de ulceração e hiperêmico, sendo realizado novo procedimento cirúrgico na tentativa de retirada da massa tumoral recidivante. Após o terceiro procedimento, o animal acordou da anestesia, vindo a óbito em 24 horas de pós-operatório e este foi encaminhado para exame post mortem. A necropsia revelou discreta redução do escore corporal e aumento na região torácica de pele. Identificouse tumor cutâneo atingindo as regiões torácica direita em toda sua extensão e esternal, caráter infiltrativo, de consistência gelatinosa e macia, com áreas vermelhas e brancas, sem limites definidos e com 
conteúdo hemorrágico (Figura 3). Ao que toque da massa tumoral percebeu-se em algumas áreas um líquido claro viscoso. Observou-se também, edema subcutâneo na região do membro torácico direito. $\mathrm{O}$ coração apresentava hipertrofia cardíaca concêntrica do ventrículo esquerdo, endocardiose moderada de mitral com lesões de refluxo.

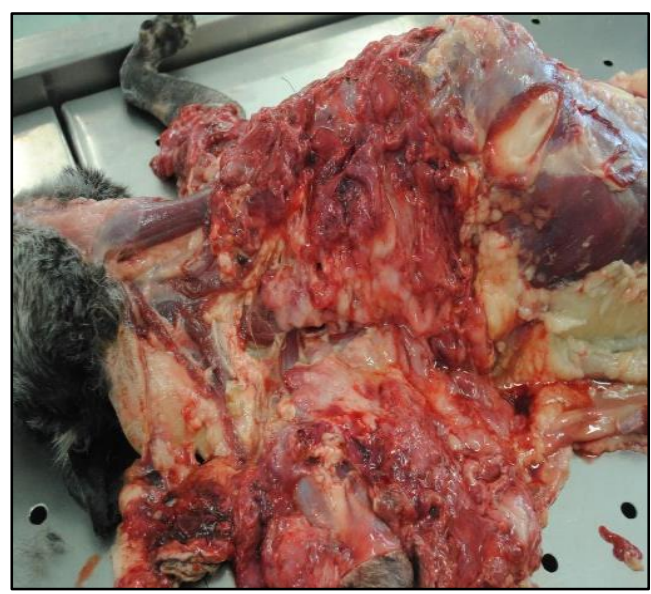

Figura 3. Cadela, SRD com regiões do peito e tórax direito com neoplasia extensa, não delimitada, formada por áreas brancas macias (entre colchetes).

\section{Discussão}

O diagnóstico de mixossarcoma foi obtido pela apresentação clínica, achados de necropsia e pelos achados histológicos característicos desta neoplasia. Existem poucos relatos de MXS em cães, a grande maioria acometendo tecido subcutâneo de tronco e membros (Fernandes et al., 2015; Goldschmidt \& Hendrick, 2008). Entretanto, acometimento de baço, cavidade abdominal, plexo braquial, entre outros locais, já foram descritos (Braz et al., 2015; Maria \& Manzan, 2003; Zambarda et al., 2017). A localização do tumor apresentado no relato corresponde ao comumente relatado em caninos. Sendo descrita como uma neoplasia rara, maligna e com pouco potencial metastático. O diagnóstico é realizado através de exame histopatológico e o tratamento cirúrgico amplo é o de eleição (Daleck et al., 2016; Liptak \& Withrow, 2007; Meuten, 2002).

Em estudo publicado por Fernandes et al. (2015) é descrita uma análise retrospectiva de um período de 10 anos, onde são descritos 549 casos de neoplasias cutâneas diagnosticadas através de exame histopatológico e apenas três casos foram diagnosticados como MXS, todos em cães idosos. Silveira et al. (2012) realizaram um levantamento de um período de 30 anos (1978-2008) com o objetivo de relatar e quantificar a ocorrência de neoplasias, em um total de 1668 casos apenas dois diagnosticaram mixossarcoma. Estes levantamentos demonstraram a baixa ocorrência do tipo tumoral diagnosticado na paciente deste relato.

Exames radiológicos da região torácica são indicados para investigação de possíveis metástases (Foale \& Demetriou, 2010); porém, a tutora não autorizou a realização destes, não sendo possível o estadiamento clínico ante mortem. Apesar de maligno, acredita-se que o mixossarcoma tenha baixa capacidade de gerar metástases (Liptak \& Withrow, 2007), condizente com ausência de metástases durante avaliação do pulmão e linfonodos na necropsia.

A etiologia dos sarcomas de tecidos moles ainda não foi totalmente elucidada, porém em cães, tem sido associado à exposição à radiação, corpos estranhos, implantes ortopédicos, parasitismo por Spirocerca lupi e trauma (Liptak \& Withrow, 2007). Hendrick (2017) cita que as ocorrências de recidivas do tumor são normais, após a excisão cirúrgica. Todavia, segundo Dennis (2010) uma cirurgia agressiva, com uma boa margem e precoce deve ser sempre o primeiro tratamento de escolha, visto que o prognóstico pode ser melhor. Daleck et al. (2016) destaca a possibilidade de que os STM se tornem cada vez mais agressivos após tentativas subsequentes de excisão, resultando em morbidade adicional e 
maiores custos. No relato de caso exposto, o paciente foi submetido a três procedimentos cirúrgicos, em cada retorno o tumor apresentava-se mais agressivo, culminando no óbito do animal.

\section{Conclusão}

O diagnóstico por meio de exame histopatológico foi essencial para a definição de diagnóstico específico e entendimento do comportamento tumoral. O tratamento cirúrgico mostrou-se eficiente em relação a diminuição da massa tumoral, porém seu caráter infiltrativo impossibilitou a remoção completa da neoplasia. Ocorreram duas recidivas, de forma cada vez mais agressiva levando o paciente ao óbito.

\section{Agradecimentos}

Ao setor de Patologia Veterinária da Universidade Federal do Rio Grande do Sul.

\section{Referências}

Braz, P. H., Martins, A. M. Q., \& Souza, A. I. (2015). Dificuldades no diagnóstico de mixosarcoma de bexiga urinária em cão. Acta Veterinaria Brasilica, 9(2), 171-175.

Daleck, C. R., Fonseca, C. S., \& Canola, J. C. (2016). Oncologia em cães e gatos. Roca.

Dennis, R. (2010). Handbook of small animal radiology and ultrasound. Churchill Livingstone/Elsevier.

Ettinger, S. J., Fedlman, E. C., \& Taibo, R. A. (2002). Tratado de medicina interna veterinaria: enfermedades del perro y el gato. Manole.

Fernandes, C. C., Medeiros, A. A., Magalhães, G. M., Szabó, M. P. J., Queiroz, R. P., Silva, M. V. A., \& Soares, N. P. (2015). Frequência de neoplasias cutâneas em cães atendidos no hospital veterinário da Universidade Federal de Uberlândia durante os anos 2000 a 2010. Bioscience Journal, 31(2), 541548.

Foale, R. D., \& Demetriou, J. (2010). Saunders solutions in veterinary practice: Small animal oncology E-Book. Elsevier Health Sciences.

Goldschmidt, M. H., \& Hendrick, M. J. (2008). Tumors of the skin and soft tissues. In D. J. Meuten (Ed.), Tumors in Domestic Animals, Fourth Edition (pp. 45-117). Iowa State Press.

Gross, T. L., Ihrke, P. J., Walder, J. E., \& Affolter, K. V. (2009). Doenças de pele do cão e do gato: diagnóstico clínico e histopatológico. Editora Roca.

Hendrick, M. J. (2017). Mesenchymal tumors of the skin and soft tissues. In D. J. Meuten (Ed.), Tumors in domestic animals (pp. 142-175). John Wiley and Sons Inc.

Liptak, J. M., \& Withrow, S. J. (2007). Cancer of the gastrointestinal tract. In S. J. Withrow \& D. M. Wail (Eds.), Small animal clinical oncology. (pp. 455-473). Saunders Elsevier.

Maria, P. P., \& Manzan, M. R. (2003). Mixossarcoma em cavidade abdominal em Boxer. Relato de caso. Brazilian Journal of Veterinary Research and Animal Science, 40, 212-213. https://doi.org/10.11606/issn.2318-3659.

Meuten, D. J. (2002). Tumors of the skin and soft tissues. Iowa Satate Press.

Meuten, D. J. (2016). Tumors in domestic animals. John Wiley \& Sons.

Silveira, M. F., Gamba, C. O., Guim, T. N., Bonel-Raposo, J., \& Fernandes, C. G. (2012). Características epidemiológicas de sarcomas de tecidos moles caninos e felinos: levantamento de 30 anos. Revista Acadêmica Ciência Animal, 10(4), 361-365. https://doi.org/10.7213/academica.7742.

Zambarda, T. T., Souza, M. J., Cannavon, J. M., Felten, C., Pavarini, S. P., \& Pöppl, Á. G. (2017). Mixossarcoma esplênico em cão. Acta Scientiae Veterinariae, 45, 1-4.

Histórico do artigo:

Recebido: 12 de janeiro de 2021

Aprovado: 18 de fevereiro de 2021.
Licenciamento: Este artigo é publicado na modalidade Acesso Aberto sob a licença Creative Commons Atribuição 4.0 (CC-BY 4.0), a qual permite uso irrestrito, distribuição, reprodução em qualquer meio,

desde que $o$ autore a fonte sejam devidamente creditados. 